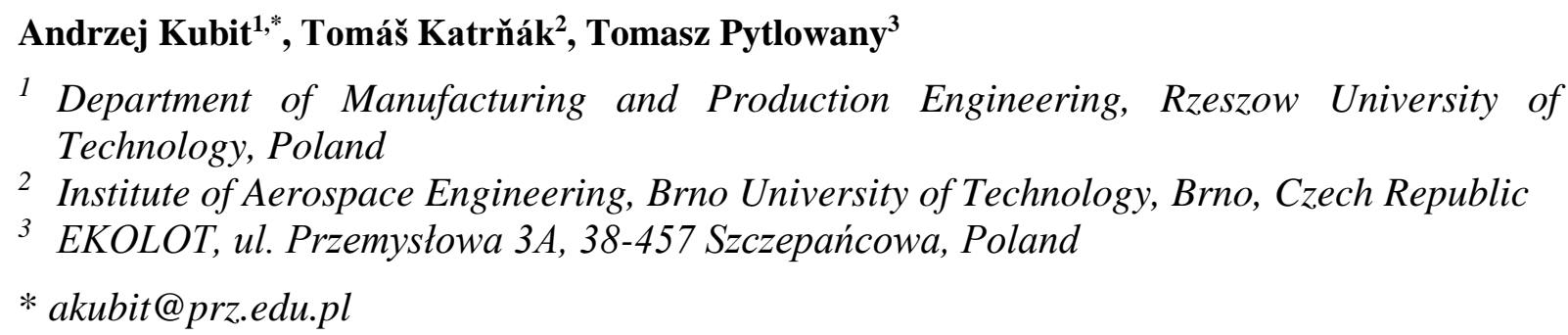

\title{
INFLUENCE OF THE TYPE OF ADHESIVE ON THE PROPERTIES OF THE GFRP COMPOSITE ADHESIVE JOINT, DETERMINED ON THE BASIS OF THE STATIC T-PEEL TEST
}

\begin{abstract}
The article presents the results of experimental studies determining the influence of the type of adhesive on the static strength properties of the Glass Fiber Reinforced Polymer (GFRP) composite joint determined on the basis of the T-peel test. As part of the static tests on peeling joints, a comparison of peak load and stiffness for individual joints was made. The fracture surfaces were also analyzed, showing various failure mechanisms. It was shown that the variant of joints made with the Enguard BP72A polyester adhesive was characterized by the highest strength properties with a mean peak load of $836.73 \mathrm{~N}$.
\end{abstract}

Keywords: GFRP composites; adhesive joints; T-peel test; failure analisys

\section{INTRODUCTION}

Composite structures based on fiber reinforced polymers (FRP) are more and more widely used in the construction of structures in aviation, automotive, shipbuilding, as well as, among others, in wind energy $[1,2]$. Composite materials are also very often used to repair existing structures [3, 4]. GFRP composites are widely used in architectural applications, among others roofing and partition walls are made of them $[5,6]$. This is due to the very attractive properties of this type of composites, and above all, it is about high specific strength. Therefore, composites are often used in the construction of structures which require low weight while maintaining high strength [7].

The considered composites are composed of two main components, namely the plastic matrix and the reinforcement fibers that carry the load [8-10].

The principle of operation of FRP composites is based on the transfer of loads by various types of fibers. The matrix serves only as a binder for the fibers and direct protection against external factors. The fibers used for their production can be continuous (continuous or monofilament) or discontinuous (staple fibers, whiskers). Numerous products made of single 
fibers can also be used as reinforcement: rovings, mats, fabrics, pre-impregnates, shaped elements $[11,12]$.

Currently, a significant limitation in the use of GFRP composites in mass industry is the technology that requires a lot of work, which makes the production costs relatively high. Another problem is the disposal of used composite products based on irreversibly hardened epoxy or polyester resins [1]. However, despite certain limitations, composites are consistently increasingly used in responsible, high-strength and lightweight structures. With the development of the use of polymer-fiber composites, design solutions, including combinations of such materials, develop. Generally, in thin-walled composite structures similar technologies are used as in this type of structures made of metals, i.e. riveting and adhesive bonding are used, while composites with a thermoplastic matrix are resistively welded [13]. Regarding the riveting technology, which works well in metal structures, it is less effective for composites, because by making rivet holes, the continuity of the fibers is broken, which reduces the load capacity of the structure. The riveted holes make the structure highly susceptible to the initiation of fatigue processes, and finally, metal rivets lead to an increase in the structure mass $[14,15]$. Resistance welding cannot be used for joining composites with a matrix of epoxy or polyester resins. Adhesive joints seem to be a favorable form of joining elements of composite structures. These types of joints do not introduce holes, stress concentrators, ensure uniform distribution of stresses, and due to the thin layer of adhesive, in practice they do not increase the weight of the structure. Ensuring a high-quality adhesive bond requires proper preparation of the surfaces of the joined materials. The authors of the works $[16,17]$ have carried out a series of studies on the influence of the surface properties of polymer-fiber composites on the effectiveness of adhesive bonds. The strength of the structure in which there are adhesive joints is extremely influenced by the configuration of these joints. Research on the influence of various configurations of adhesive bonding composite structures was studied by Adams et al. [18] and Godzimirski et al. [19]. For FRP composite joints, ASTM D5573 [20] distinguishes seven common failure cases. They are: adhesive failure, cohesive failure, thin-layer cohesive failure, fiber-tear failure, light-fiber-tear failure, stock-break failure, or mixed failure. The mechanism of failure of the adhesive joint is influenced by a number of factors, ranging from the quality of the composite, the adhesive used, the joining technology, surface preparation, etc. The authors of [21-28] raised the issue of the influence of various factors, incl. edge chamfering, influence of various environmental conditions, surface contamination, surface treatment with plasma on the way of joint failure. Due to the multitude of factors influencing the failure mode of composite joints, it is difficult to predict the form of failure. The authors of the works [29-33] made attempts to predict the manner of failure of the adhesive joints of GFRP composites.

This paper describes experimental studies in which the influence of various adhesives on the failure mechanism and the strength of the joints of GFRP composites in the static peel test was determined. Floating roller peel tests described in the ASTM D3167 standard [34] are commonly used to test the strength of adhesive joints under peel conditions in relation to FRP composites. Riul et al. [35] described the experimental tests carried out with this method, which were aimed at determining the strength of the joints of composites produced with various methods. An equally common method of testing the peel strength of adhesive joints is the T-peel test. It is characterized by the fact that it does not require the use of additional devices, and the preparation of samples is not complicated, hence it is a simple method, and therefore often used [36,37].

This method was adopted in the paper as an effective way to determine the properties of GFRP composites joints. 


\section{MATERIALS AND METHODS}

This paper deals with the issue of determining the parameters of adhesive for the wing parts made of GFRP composites of the aircraft produced by the manufacturer of light-sport aircraft (LSA), the Ekolot company (Krosno, Poland).

The research was carried out for the joints of GFRP composites with a matrix of vinyl ester resin. For the preparation of the composites, four layers of Interglas 92125 glass fabric were used, a double $2 / 2$ weave with a grammage of $280 \mathrm{~g} / \mathrm{m}^{2}$, additionally, a delaminating fabric was used for the first surface. The arrangement of the fibers was $+/-45^{\circ}$. The matrix of the laminating composite was vinyl ester resin, however, the detailed composition of the resin is a trade secret of the manufacturer.

Lamination was carried out in a mold giving an angle shape approximately $180 \mathrm{~mm}$ wide (Fig. 1a).

In the hardening process, the vacuum pressure method was used, after hardening, a composite $1.4 \mathrm{~mm}$ thick was obtained. After curing under vacuum conditions for 24 hours and after seasoning for 10 days, the composite was glued with four variants of adhesives:

Variant Adhesive_1: Enguard BP72A bonding paste polyester adhesive.

Variant V2: Enguard BP06AW bonding paste polyester adhesive.

Variant V3: vinyl ester resin, the same composition as used for lamination.

Variant V4: adhesive prepared on the basis of vinyl ester resin, with proportions identical to the use used for lamination, and filled with CAB-O-SIL TS-720 (synthetic amorphous silica) powder to obtain a uniform adhesive.

After curing, the joint was cut open with a band saw for samples having a width of 30 $\mathrm{mm}$, thereby obtaining T-peel test samples having the shape and dimensions shown in Figure $1 \mathrm{~b}$.
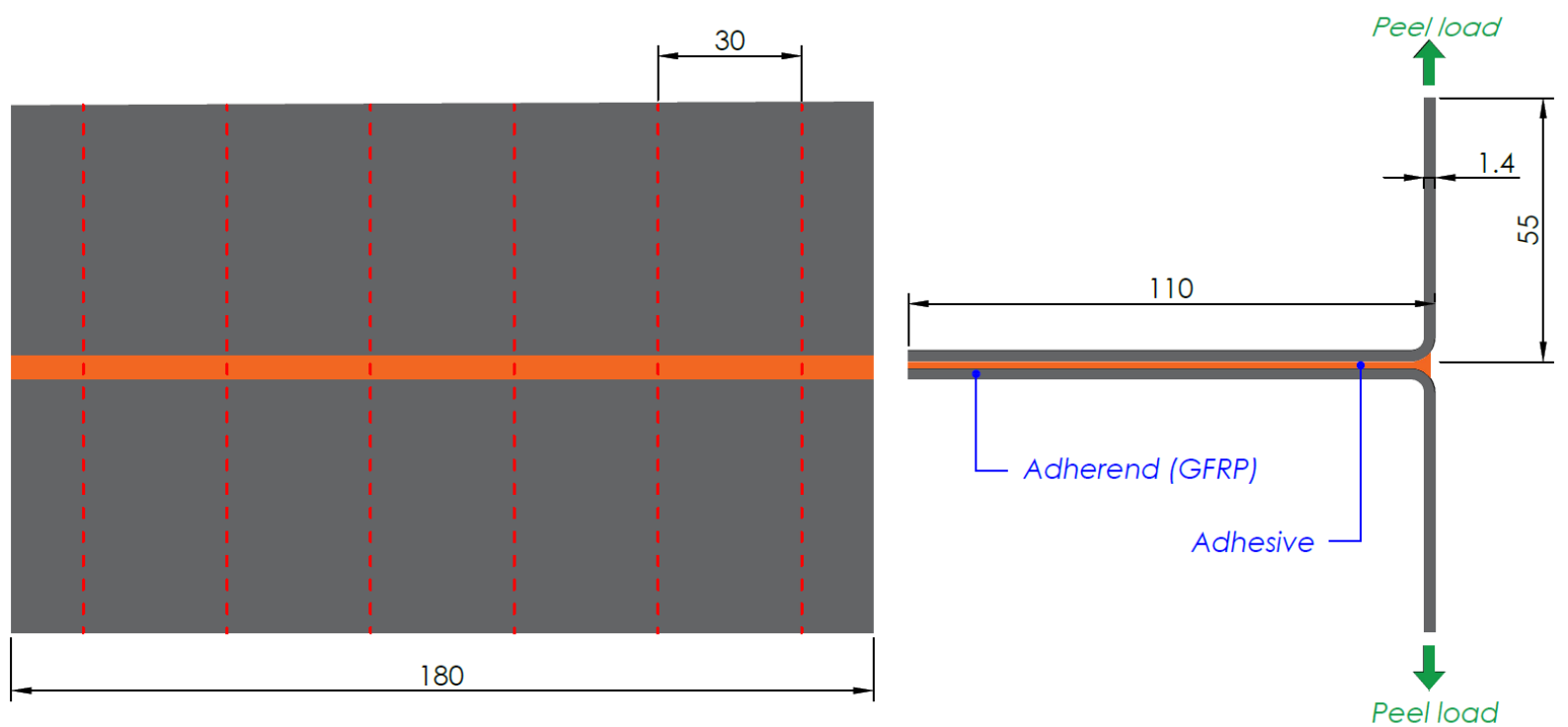

Fig. 1. Geometry of T-peel test specimen: (a) before cutting into individual specimens;

(b) specimen dimensions (dimensions in $\mathrm{mm}$ )

T-peel tests were conducted according to the recommendations of the ASTM D 1876 standard [36]. The tests of the static peel strength were carried out on the Zwick/Roell Z100 testing machine, the test rate was $100 \mathrm{~mm} / \mathrm{min}$. The static strength tests were carried out at room temperature. Five repetitions were carried out for each of the considered variants. 
The morphologies of the fracture surfaces of the adherends were examined using an scanning electron microscope (SEM) Phenom ProX (Nanoscience Instruments, Phoenix, AZ, USA).

\section{RESULTS}

Figure 2 shows a graph containing representative static peel test curves for the considered joint variants. On the basis of the peel curves, it can be concluded that in practically every variant of the joint, the peak load value is significantly higher than the basic, average value of the peel force. This is due to, inter alia, the fact that the samples did not remove the flash in the front part of the joint, which significantly strengthens them.

When analyzing the peel curves for the T-peel test, differences in the stiffness of individual joints can be observed. To visualize the onset of the peel curves, Figure 3 shows the same curves but within a narrowed displacement range, i.e. 0-2.5 $\mathrm{mm}$. On this basis, it can be observed that the joint made with Adhesive_2 is characterized by the lowest stiffness among the considered adhesives. The other joint variants have comparable stiffness.

Another conclusion from the peel curve analysis is that each of the adhesive fillers used, i.e. in the case of Enguard BP06AW it was a light mineral filler (variant Adhesive_2), while in the case of vinyl ester resin, synthetic amorphous silica (variant Adhesive_4), lead to reduce the strength of the joint, as demonstrated here on the basis of relatively low peak load values.

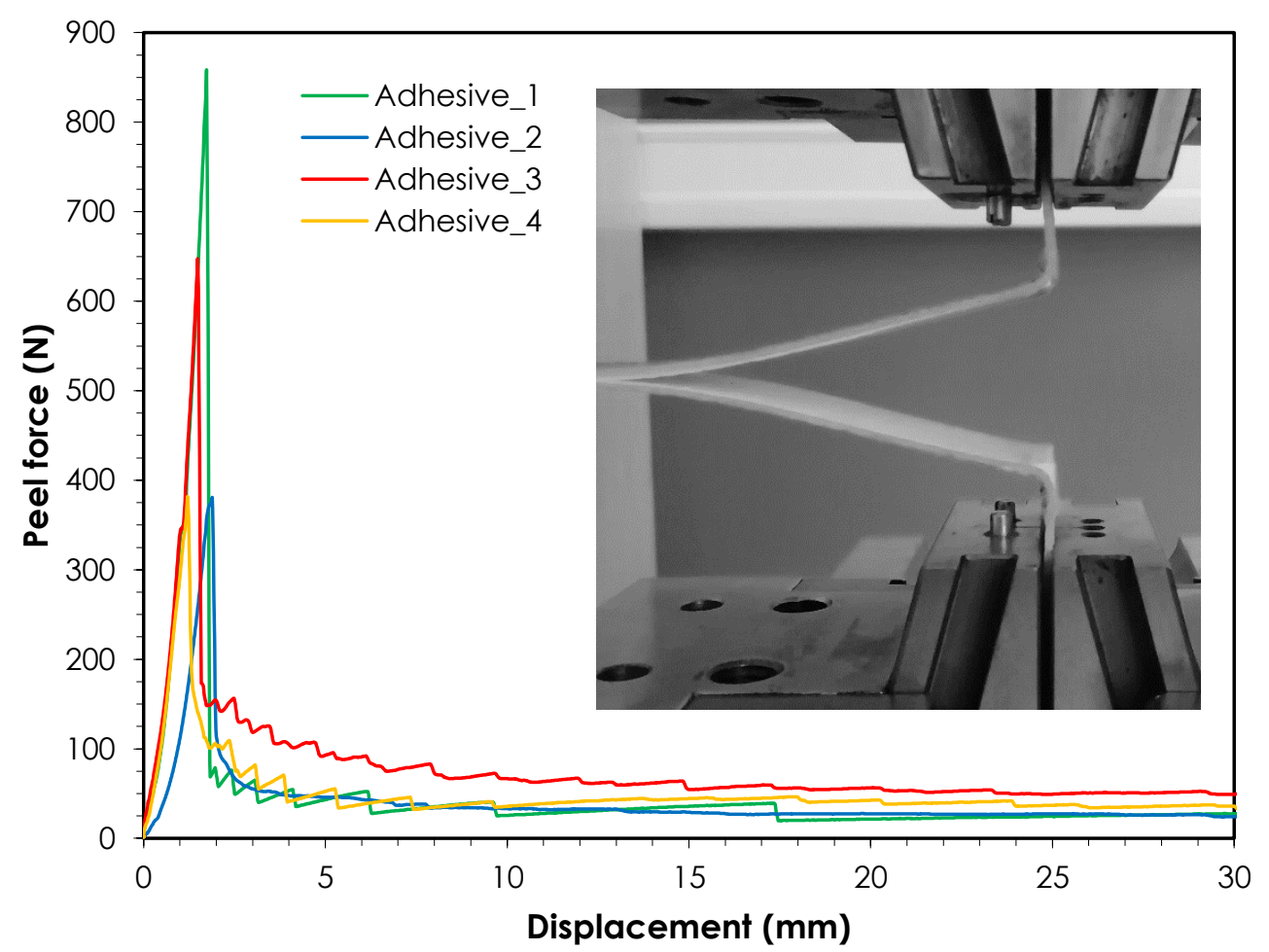

Fig. 2. Typical force-displacement curves of T-peel test for adhesives studied 


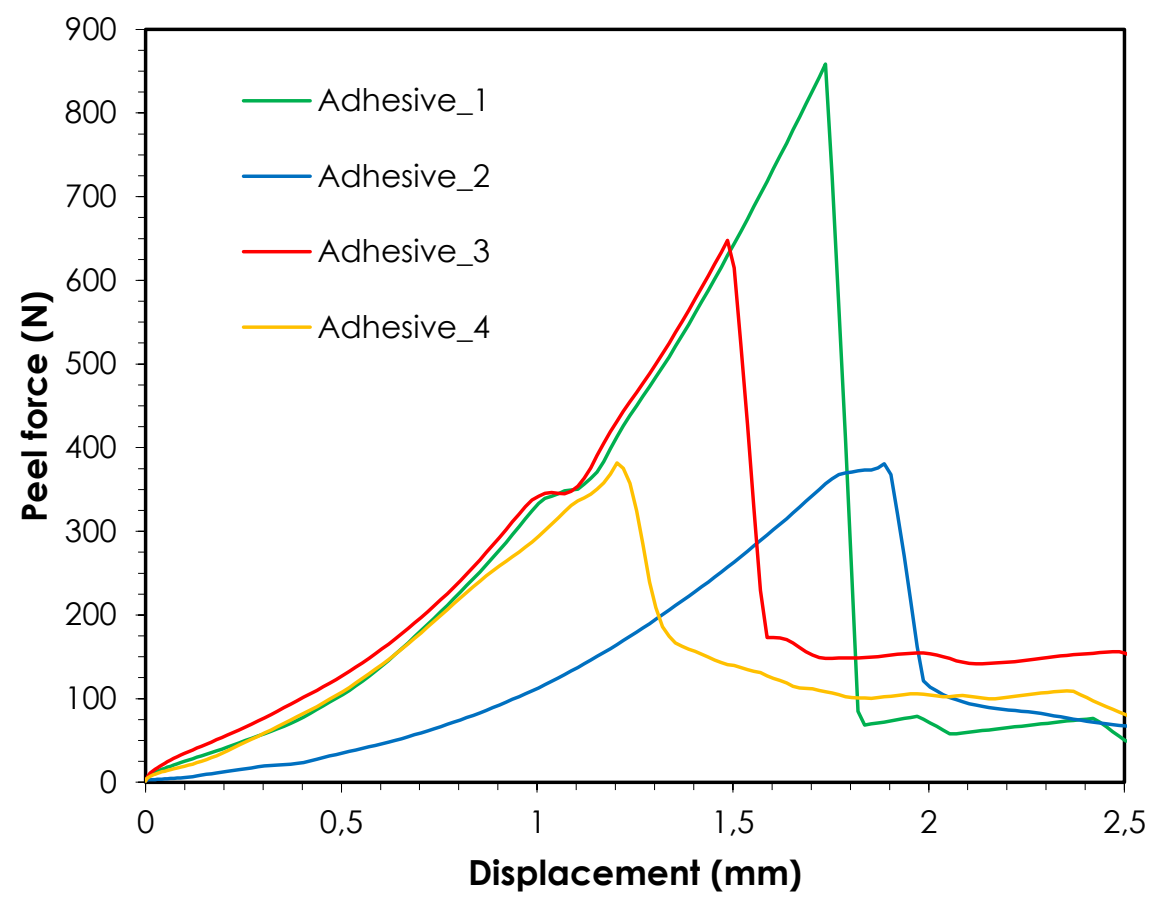

Fig. 3. Initial fragment of T-peel test curves showing differences in stiffness of individual adhesives in the initial phase of peel

Moving on to the statistical analysis of the obtained results, the Figure 4 shows a bar chart which summarizes the average peak load values for individual variants with the standard deviation value marked. It has been shown that the variant of joints made with Adhesive_1 is characterized by the highest repeatability of the obtained results. With an average peak load value of $836.73 \mathrm{~N}$, the standard deviation was $18.06 \mathrm{~N}$. The Adhesive_3 variant is also satisfactory, with an average peak load value of $651.29 \mathrm{~N}$ with a standard deviation of 25.64 N. Definitely the lowest repeatability of the peel strength was demonstrated for the joint made of vinyl ester resin filled with silica (variant Adhesive_4). In this case, the average peak load value was $409.72 \mathrm{~N}$ and the standard deviation was $72.23 \mathrm{~N}$. The effect of such a low repeatability for joints in the Adhesive_4 variant may be uneven distribution of the filler in the resin structure.

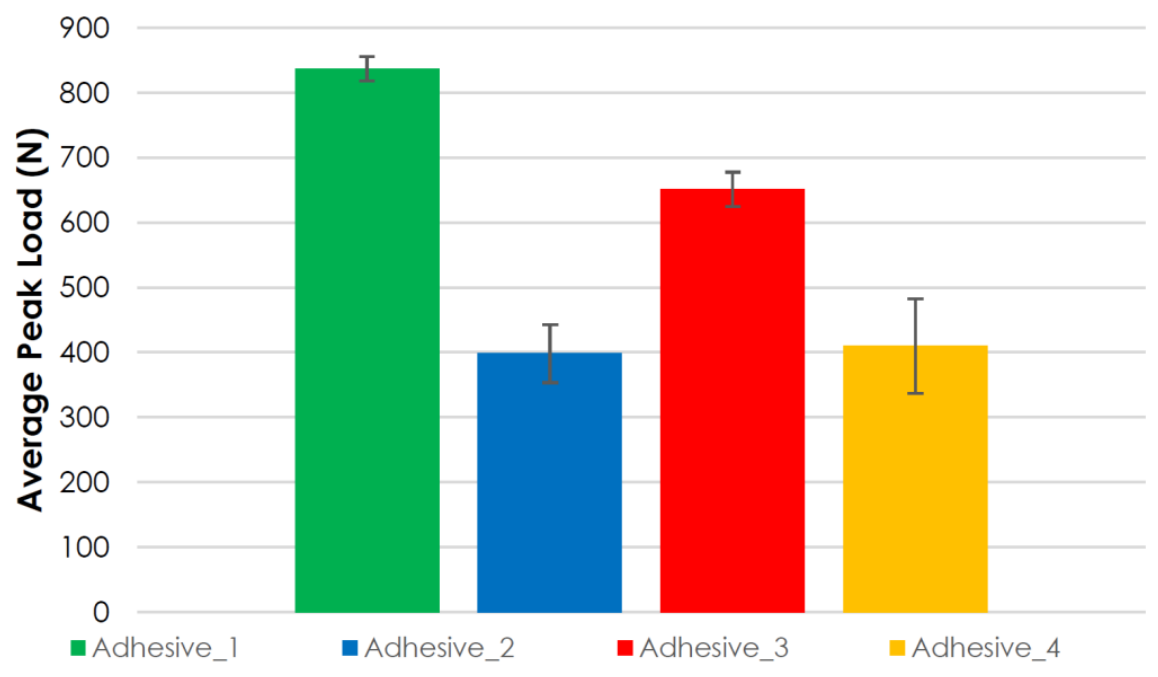

Fig. 4. Average values of peak load for adhesives studied 
a)

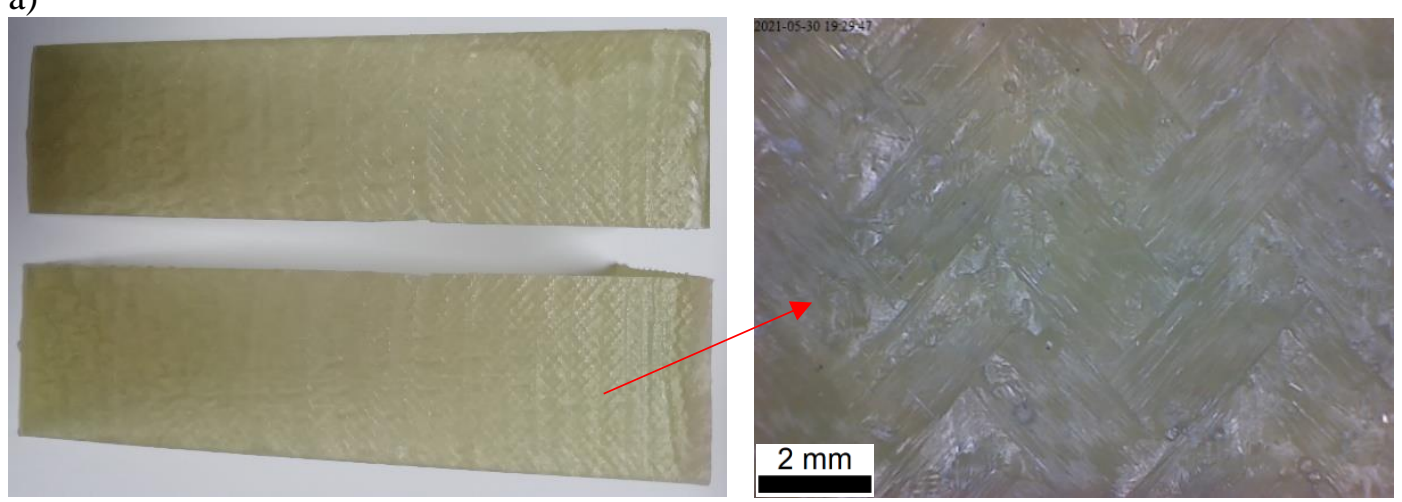

b)

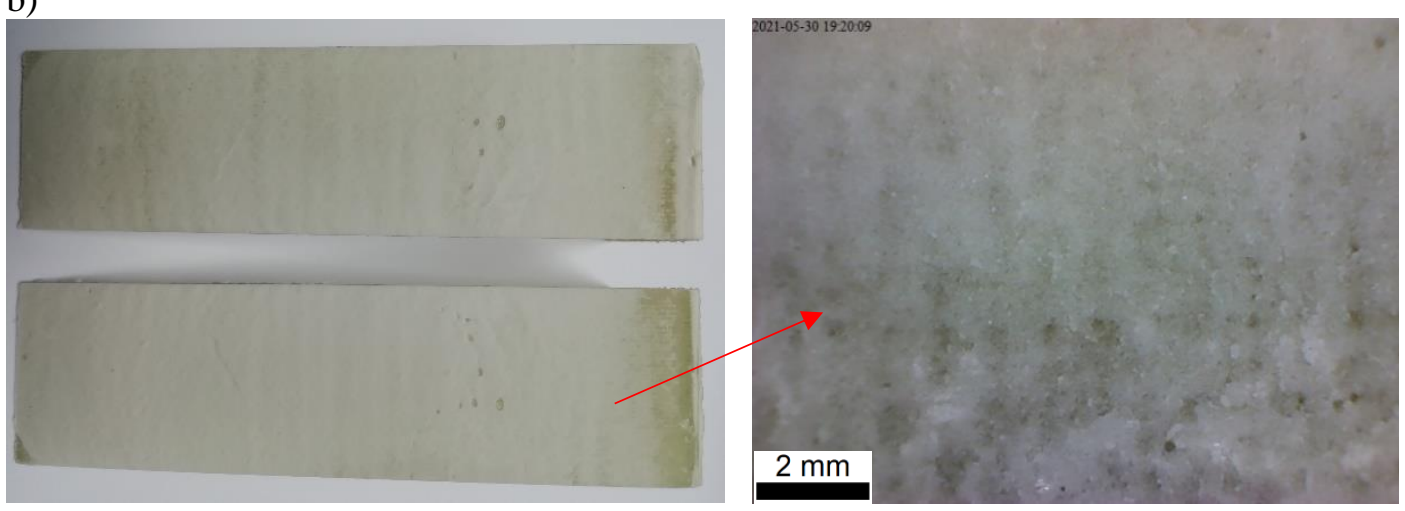

c)
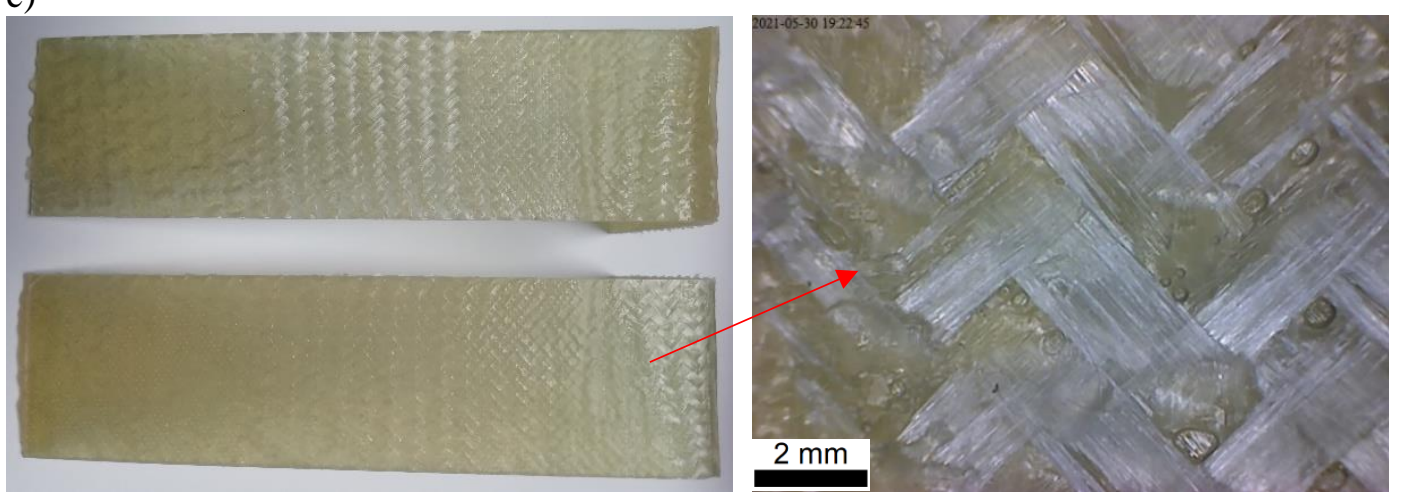

d)
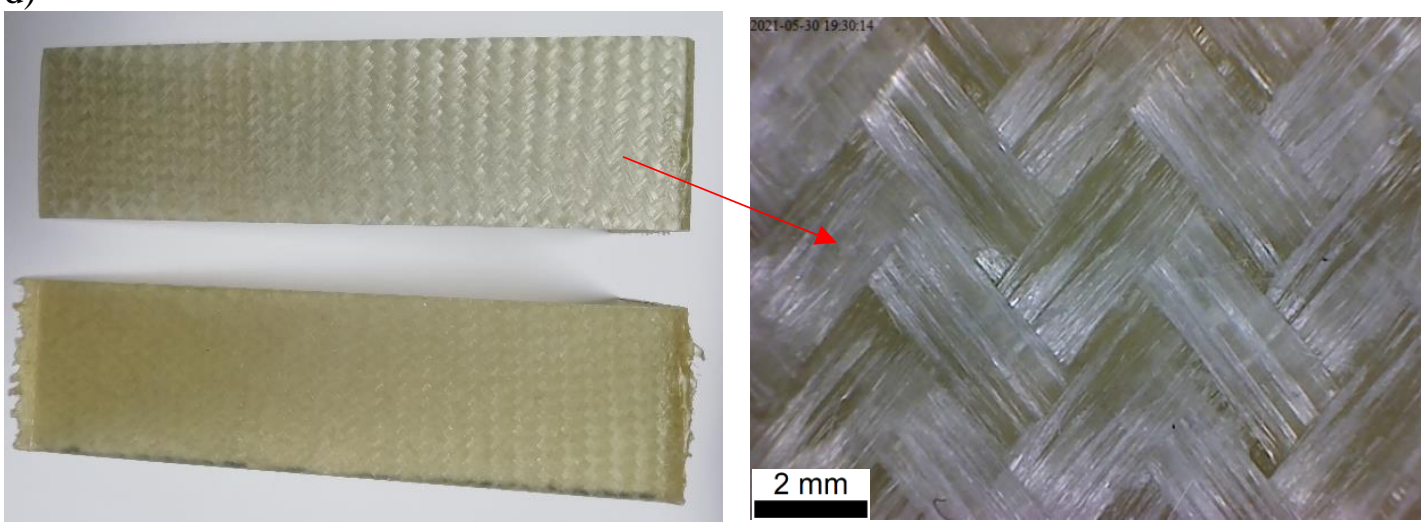

Fig. 5. View of the typical fracture surfaces of adhesive joints for variants: (a) Adhesive_1; (b) Adhesive_2; (c) Adhesive_3; (d) Adhesive_4 
By analyzing the surface of failure of joints on a macroscopic scale, it is possible to indicate the mode of failure typical for given variants of joints. Figure 5 shows the views of the fracture surfaces of the joint of both adherends and the enlarged view of the front part of the joint. In the case of joints made with both Enguard adhesives (variants Adhesive_1 and Adhesive_2), a typical cohesive failure was demonstrated (Figs. 5a, b). Which in the case of adhesive joints is the desired mode of failure. For the variant where the joint was made with the unmodified resin used for lamination (variant Adhesive_3), light-fiber-tear failure was achieved by detaching the matrix from the surface of the fibers (Fig. 5d). Thus, there is a strong bond between the previously hardened matrix resin and the resin used as a adhesive with identical properties.. This joint was so strong that the adhesive between the laminate matrix and fibers obtained in the technological lamination process was damaged. In the case of a resin-based adhesive that was filled (Adhesive_4 variant), adhesive failure was obtained on the majority of the joint surface, while a small area of light-fiber-tear failure was shown in the front part of the joint (Fig. 5c).

Joint failure surfaces were also observed on a microscopic scale. For this purpose, SEM microscopy was used to make fractographs. On the basis of the fracture surface view in the case of samples joined with Adhesive_1, it was observed that despite the dominant cohesive failure (Fig. 6a), small areas of adhesive failure can be seen on the failure surface, as shown in Figure 6b. The composite surface is visible here from the adhesive was separated. This type of failure of the adhesive joints of CFRP (Carbon Fiber Reinforced Polymer) composites was also demonstrated by the authors of the work [33].

a)

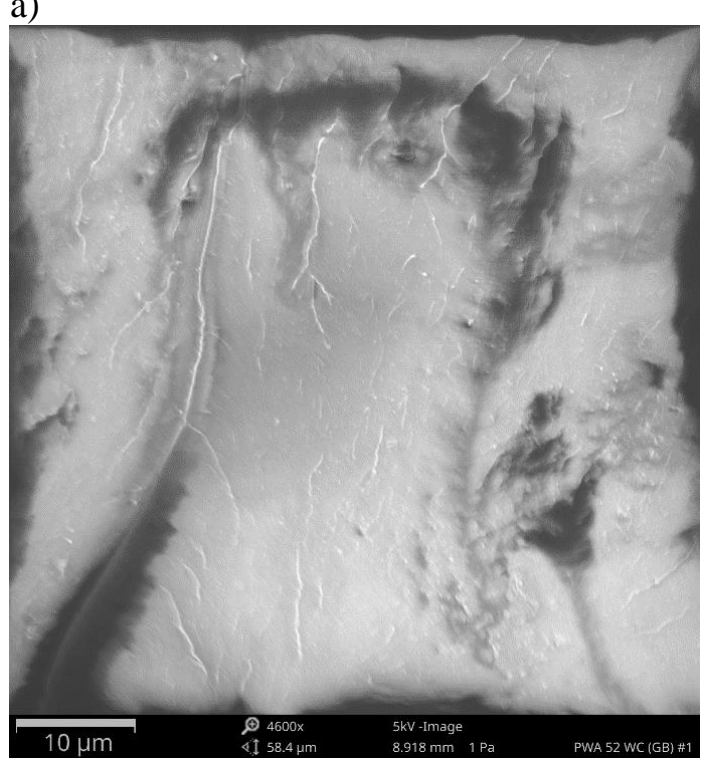

b)

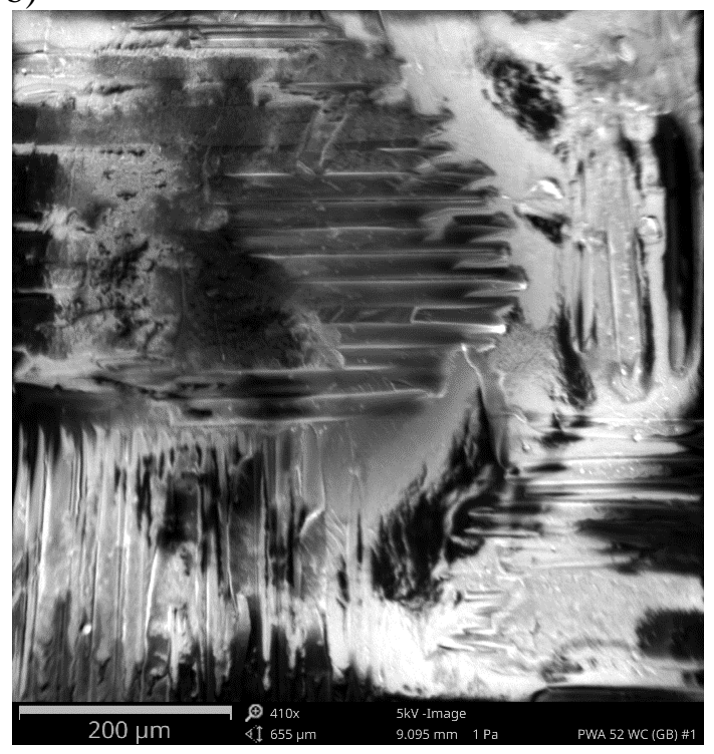

Fig. 6. SEM images of selected areas of fracture surfaces of for the specimen joined with Adhesive_1: (a) cohesive failure; (b) adhesive failure

Moving on to the SEM fractography analysis for joints produced with the use of the Adhesive_2 variant, the fully cohesive nature of joint failure was confirmed. On the both surfaces of adherends the characteristic filler was observed (Figs. 7a, b). The visible filler is hollow mineral objects aimed at reducing the mass of adhesive structures. It can be observed that the filler has a high adhesion to the adhesive. As can be seen in the fractography, the filler particles have different sizes and when the joint failures, they also crack. Since the failure of 
the adhesive structure also occurs through cracking of the filler particles, and its particles are hollow, it can be concluded that to some extent the filler leads to a decrease in the adhesive strength, which was confirmed by the results of static strength tests. These types of fillers with particle sizes in the order of $10^{-6} \mathrm{~m}$ usually have a negative effect on the strength of the joints [38-39], but are nevertheless used due to other desirable properties, such as reduction of joint mass, electrical and thermal conductivity of the joint, etc.

a)

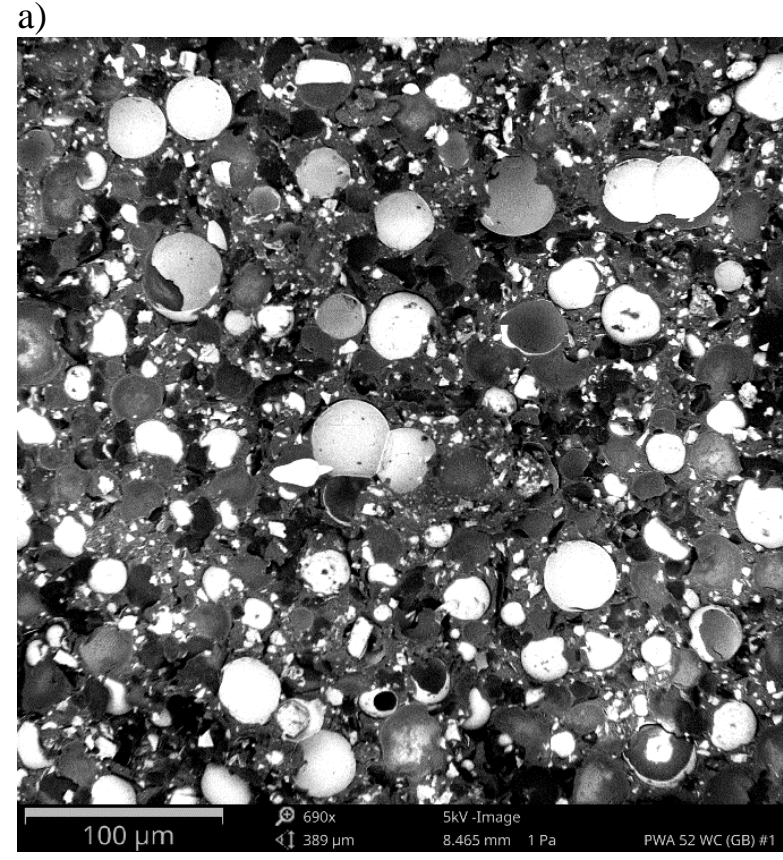

b)

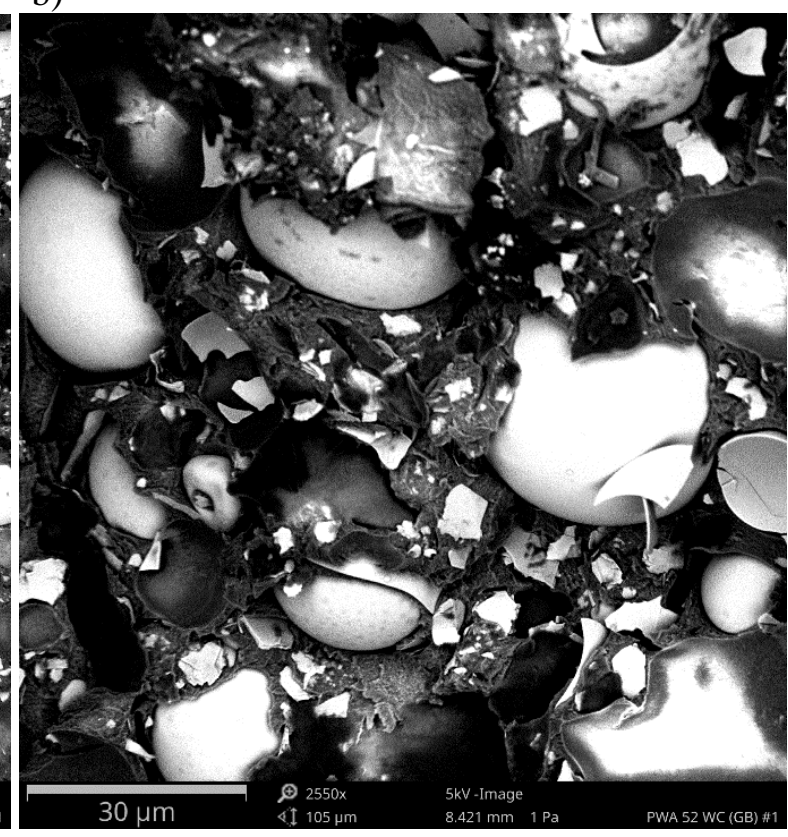

Fig. 7. SEM fractographs for the Adhesive_2 variant showing cohesive failure with visible particles of adhesive filler at different magnification (a) 690x and (b) 2550x

The adhesive with mineral filler used in the work is usually used where a thick layer of the joint is required or as a putty to fill in unevenness, therefore it is important that its mass is as low as possible. Hollow, thin-walled spherical structures cracking during the failure of the joint, cause the cohesive character of cracking in the adhesive joint. It is also caused by the fact that in the joint plane due to the hollow thin-walled filler particles, there is less active adhesive surface. A similar nature of the failure of adhesive joints with fillers was demonstrated by the authors of [39], who investigated the effect of the filler content on the strength of joints of aluminium alloy sheets.

In the case of joints made with non-filled vinyl ester resin, identical to the one used in the lamination process, which is the matrix of the composite, SEM micrograph analysis showed light-fiber-tear failure, which confirms the conclusions obtained on the basis of the macroscopic analysis. The surface fractography for the Adhesive_3 variant showed completely exposed fibers on the entire surface of one of the adherends. Figs. 8a, b show the fracture surfaces of the beginning and end portions of the joint, respectively. The visible, exposed fibers prove that the failure took place here by breaking the adhesive connection between the fibers and the matrix. The resin used to bond the previously laminated composites was thus characterized by high adhesion, creating a structurally uniform mass with the matrix.

A similar nature of failure was demonstrated for the adhesive in the form of filled vinyl ester resin (Adhesive_4), but only in the frontal part of the joint (Fig. 8c). Further from the face of the joint, the cohesive nature of the failure was demonstrated (Fig. 8d), which proves 
that the powder used to thicken the resin weakens the hardened structure. This is confirmed by the results of static strength tests, which showed that the joints produced with the considered adhesive, are characterized by the lowest strength among the considered variants. The front of joint was defined as a distance of up to $10 \mathrm{~mm}$ from the leading edge of the joint, and the end of joint was defined as the area approximately $90 \mathrm{~mm}$ from the face of the joint.

a)

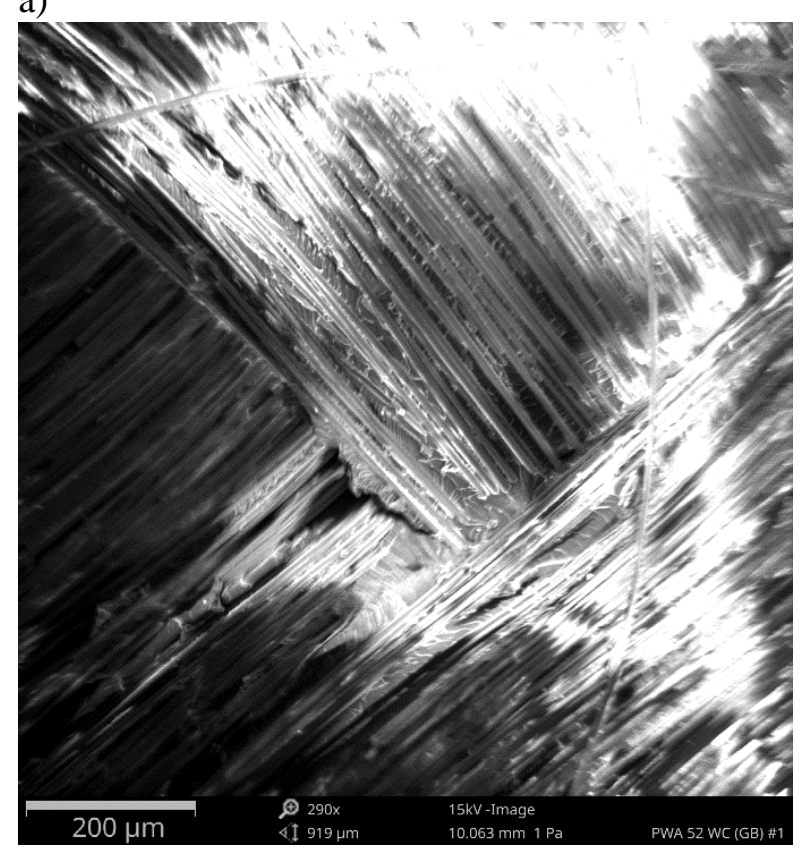

c)

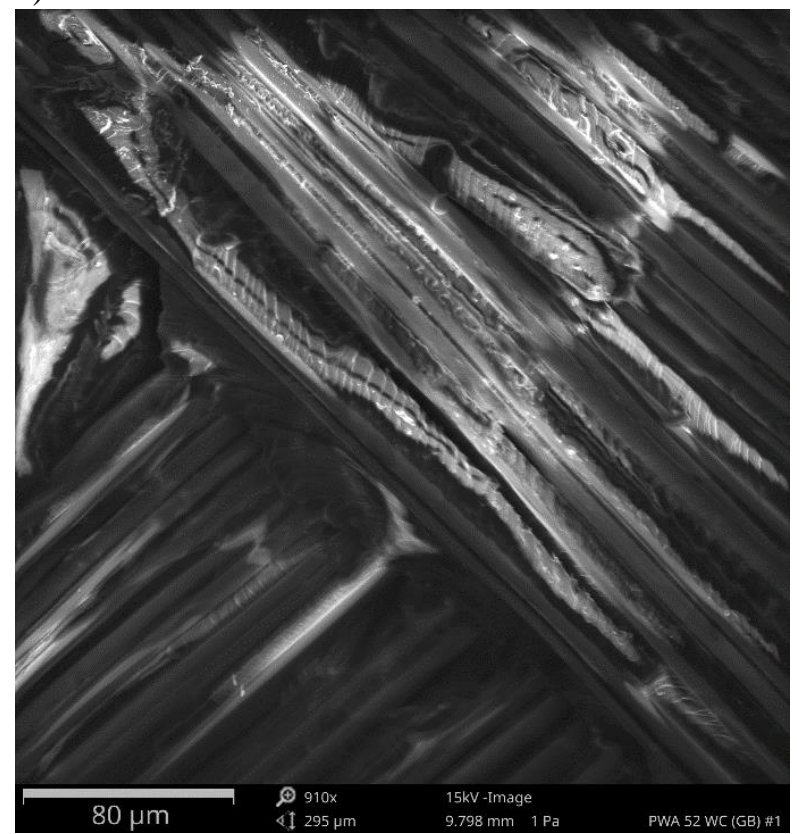

b)

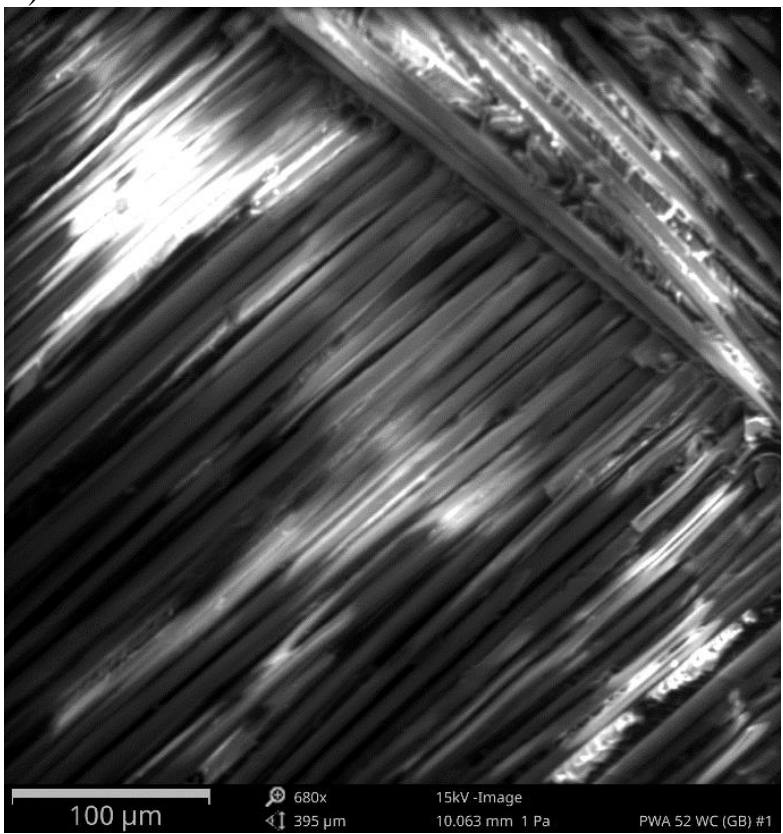

d)

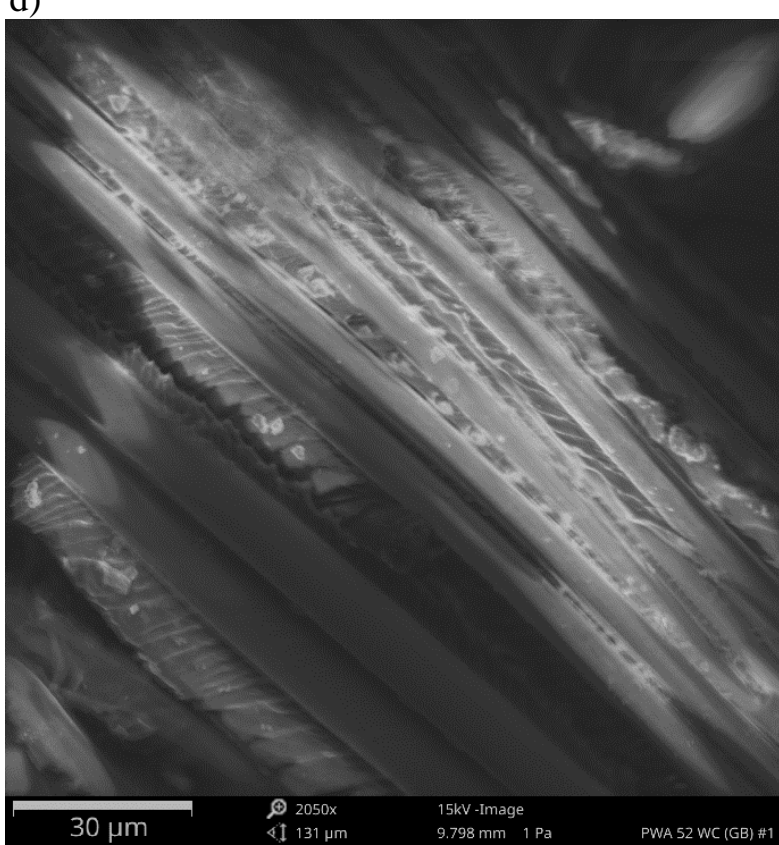

Fig. 8. SEM images of fracture surfaces of adherends for: (a) front part of joint - variant Adhesive 3; (b) end part of joint - wariant Adhesive_3; (c) front part of joint - variant Adhesive_4; (d) end part of joint - variant Adhesive_4 


\section{CONCLUSIONS}

The paper presents the results of tests of the peel strength of adhesive joints of GFRP composites depending on the adhesive used. This is an important issue because composites of this type are more and more widely used in light, durable structures, and therefore there is a need to joining them. Adhesive bonding is a common method of joining composite structures. The conclusions from the conducted research can be summarized as follows:

1. It was shown that the variant of joints made with the Enguard BP72A bonding paste polyester adhesive was characterized by the highest repeatability of the obtained results. With a mean peak load of $836.73 \mathrm{~N}$, the standard deviation was $18.06 \mathrm{~N}$.

2. The largest dispersion of the peel strength results was demonstrated for the combination made of vinyl ester resin filled with synthetic amorphous silica. In this case, the mean peak load value was $409.72 \mathrm{~N}$ and the standard deviation was $72.23 \mathrm{~N}$. The effect of such low repeatability for joints in the Adhesive_4 variant may be uneven distribution of the filler in the resin structure.

3. Each of the joints made with filler-containing adhesives, i.e. Enguard BP06AW polyester bonding paste and silica-thickened vinyl ester resin, exhibited relatively low strength compared to similar unfilled adhesives. Thus, the fillers reduce the strength properties of the joints.

4. The dominant mode of failure of joints made with the use of Enguard BP72A bonding paste and Enguard BP06AW bonding paste polyester adhesives was cohesive failure. This proves the good adhesion of these adhesives to the surfaces of the tested GFRP composites.

5. In the case of joints made with non-filled vinyl ester resin, identical to that used in the lamination process, which is the matrix of the composite, SEM micrograph analysis showed light-fiber-tear failure.

6. The adhesive joints made with the use of compacted vinyl ester resin were largely damaged by cohesive failure, which was confirmed by the weakening of the hardened resin by the synthetic amorphous silica filler used.

\section{REFERENCES}

1. Bledzki A.K., Seidlitz H., Krenz J., Goracy K., Urbaniak M., Rösch J.J. Recycling of Carbon Fiber Reinforced Composite Polymers-Review-Part 2: Recovery and Application of Recycled Carbon Fibers. Polymers, 12, 2020, 3003, 1-10

2. Dorigato A.. Recycling of thermosetting composites for wind blade application. Advanced Industrial and Engineering Polymer Research, 4(2), 2021, 116-132.

3. Katnam K.B., da Silva L.F.M., Young T.M. Bonded repair of composite aircraft structures: a review of scientific challenges and opportunities. Progress in Aerospace Sciences 61, 2013, 2642.

4. Baldan A. Adhesively-bonded joints and repairs in metallic alloys, polymers and composite materials: adhesives, adhesion theories and surface pretreatment. Journal of Materials Science 39(1), 2004, pp. 1-49.

5. Abdalla H.A. Evaluation of deflection in concreto members reinforced with fiber reinforced polymer (FRP) bars. Composite Structures, 56, 2002, pp. 63-71. 
6. Toutanji H.A., Saafi M. Flexural behavior of concrete beams reinforced with glass fiberreinforced polymer (GFRP) bars. ACI Structural Journal, 97(5), 2000, 712-719.

7. Bannister M. Challenges for composites into the next millenium - a reinforcement perspective. Composites Part A: Applied Science and Manufacturing, 32(7), 2001, 901-910.

8. Kishore R.A.; Tiwari R.; and Singh I. Investigation of drilling in $[(0 / 90) / 0] \mathrm{s}$ glass fibre reinforced plastics using taguchi method. Advances in Production Engineering and Manangement, 4(1-2), 2009, 7-46.

9. Hueber C., Horejsi K., Schledjewski R.: Review of cost estimation: methods and models for aerospace composite manufacturing. Advanc Manufact: Polymer Compos Sci. 2(1), 2016, pp. 113.

10. Doan Q.H., Thai D.K., Tran N.L. A numerical study of the effect of component dimensions on the critical buckling load of a GFRP composite strut under uniaxial compression. Materials, 13(4), 2020, 931.

11. Cintra G.G., Cardoso D.C.T., Vieira J.D. Parameters affecting local buckling response of pultruded GFRP I-columns: Experimental and numerical investigation. Composite Structures, 222, 2019, 110897.

12. Elchalakani M., Dong M., Karrech A., Li G., Ali M.S., Yang B. Experimental investigation of rectangular air-cured geopolymer concrete columns reinforced with GFRP bars and stirrups. Journal of Composites for Construction, 23, 2019, 4019011.

13. Stavrov D., Bersee H.E.N. Resistance welding of thermoplastic composites-an overview. Composites Part A: Applied Science and Manufacturing, 36(1), 2005, 39-54.

14. Holden R, Haworth P, Kendrick I. Automated riveting cell for A320 wing panels with improved throughput and reliability (SA2). SAE Technical Paper 2007-01-3915, 2007.

15. Banea M.D., da Silva L.F.M. Adhesively bonded joints in composite materials: an overview, Proceedings of the Institution of Mechanical Engineers: Part L, 223, 2008, 1-18.

16. Baldan A. Adhesively-bonded joints and repairs in metallic alloys, polymers and composite materials: adhesives, adhesion theories and surface pretreatment. Journal of Materials Science, 39(1), 2004, 1-49.

17. Rośkowicz M, Smal T. The use of composite adhesives in repairing of aircraft semi-monocoque airframe. Proceedings of the 15th European Conference on Composite Materials, Venice, 2428.06.2012.

18. Adams R. D. and WakeW. C. Structural adhesive joints in engineering, 1984, vol. 15 (Elsevier, New York).

19. Godzimirski J., Komorek A., Smal T. Research of strength features of adhesive composites (In Polish). Maintenance Problems of Machines, 1(64), 2007, 157-165.

20. ASTM D 5573-99. Standard practice for classifying failure modes in fiber-reinforced-plastic (FRP) joints. Annual Book of ASTM Standards, 15.03, 2002.

21. Kim K. S., Yoo J. S., Yi Y. M., Kim C.G. Failure mode and strength of uni-directional composite single lap bonded joints with different bonding methods. Composite Structures, 72, 2006, $477-$ 485 .

22. Kim J.K., Kim H S., Lee D.G. Investigation of optimal surface treatments for carbon/epoxy composite adhesive joints. Journal of Adhesion Science and Technology, 17(3), 2003, 329-352.

23. Zielecki W., Kubit A., Kluz R., Trzepieciński T. Investigating the influence of the chamfer and fillet on the high-cyclic fatigue strength of adhesive joint of steel parts. Journal of Adhesion Science and Technology, 31(6), 2017, 627-644. 
24. da Silva L.F.M., Öchsner A., Adams R.D. (Eds). Handbook of Adhesion Technology. Berlin: Springer 2011.

25. Rośkowicz M., Smal T. Research on durability of composite materials used in repairing aircraft components. Maintenance and Reliability 2013; 15 (4): pp. 349-355.

26. Kłonica M. Comparative analysis of effect of thermal shock on adhesive joint strength. Advances in Science and Technology Research Journal 10 (32), 2016, 263-268.

27. Kłonica M. Analysis of the effect of selected factors on the strength of adhesive joints. IOP Conference Series: Materials Science and Engineering 393 (1), 2018, 012041.

28. Qin M.H. and Dzenis Y.A. Analysis of single lap adhesive composite joints with delaminated adherends. Composites Part B: Engineering, 34(2), 2003, 167-173.

29. Kubit A., Trzepiecinski T., Kłonica M., Hebda M., Pytel M. The infuence of temperature gradient thermal shock cycles on the interlaminar shear strength of fibre metal laminate composite determined by the short beam test. Composites Part B: Engineering, 176, 2019, 107217.

30. Kumar S.B., Sivashanker S., Bag A., Sridhar I. Failure of aerospace composite scarf-joints subjected to uniaxial compression. Materials Science and Engineering A: 412(1-2), 2005, 117122.

31. Kumar S.B., Sridhar I., Sivashanker S., Osiyemi S.O., Bag A. Tensile failure of adhesively bonded CFRP composite scarf joints. Materials Science and Engineering B, 132(1-2), 2006, $113-$ 120.

32. Kim K.S., Yi Y.M., Cho G.R., Kim C.G. Failure prediction and strength improvement of unidirectional composite single lap bonded joints. Composite Structures, 82(4), 2008, 513-520.

33. Guild F.J., Potter K.D., Heinrich J., Adams R.D., Wisonm M.R. Understanding and control of adhesive crack propagation in bonded joints between carbon fibre composite adherends, II. Finite element analysis. International Journal of Adhesion and Adhesives, 21, 2001, 445-453.

34. ASTM D3167 Adhesive Floating Roller Peel Testing.

35. Riul C., Tita V., de Carvalho J., Canto R.B. Processing and mechanical properties evaluation of glass fiber-reinforced PTFE laminates. Composites Science and Technology 72, 2012, 14511458.

36. ASTM D 1876, Standard test method for peel resistance of adhesives (T-Peel Test), Volume 15.06, ASTM Standards, 1999, pp. 105-107.

37. Broughton W.R., Mera R.D. Review of durability test methods and standards for assessing long term performance of adhesive joints. NPL Report CMMT(A)61, 1997.

38. Murafa A.V., Bobyreva N.I., Khozin V.G. Modification of polyester resins with active mineral fillers. Mechanics of Composite Materials, 32(1), 1996, 86-89.

39. Ramazan K., Sunarb M., Yilbas B. Influence of adhesive thickness and filler content on the mechanical performance of aluminum single-lap joints. Journal of Materials Processing Technology, 205, 2008, 183-189. 